\title{
Carbonation of Epoxidized Methyl Soyates in Tetrabutylammonium Bromide-Based Deep Eutectic Solvents
}

\author{
Wei Liu* and Guanghui Lu \\ College of Food Science and Technology, Henan University of Technology, Lianhua Street 100, Zhengzhou 450001, P. R. CHINA
}

\begin{abstract}
Carbonated methyl soyates have been successfully prepared by cycloaddition of carbon dioxide $\left(\mathrm{CO}_{2}\right)$ to epoxidized methyl soyates in tetrabutylammonium bromide (TBAB)-based deep eutectic solvents (DES). Experimental parameters, i.e., reaction temperature, reaction time, $\mathrm{CO}_{2}$ pressure and $\mathrm{TBAB}$ concentration were evaluated. The different reaction conditions have a significant influence on the yields of carbonated methyl soyates. The use of TBAB-based DES (tetrabutylammonium bromide/triethylene glycol) significantly shortened the reaction time of the cycloaddition of $\mathrm{CO}_{2}$ to epoxidized methyl soyates. FT-IR and NMR analysis indicated that $95 \%$ of the yield of the five-membered cyclic carbonated methyl soyates were obtained at $120^{\circ} \mathrm{C}$ with $1.0 \mathrm{MPa}$ pressure of $\mathrm{CO}_{2}$.
\end{abstract}

Key words: cycloaddition, $\mathrm{CO}_{2}$, deep eutectic solvents, $\mathrm{TBAB}$, epoxidized methyl soyates

\section{Introduction}

Cyclic carbonates are one of the useful fine chemical products. Because of their advantages of high boiling point, excellent biodegradability and solubility, cyclic carbonates are widely used as a kind of main raw material for polycarbonates ${ }^{1)}$ and other plastics industries, such as non-isocyanate polyurethanes ${ }^{2}$. Five-membered cyclic carbonates, as a member of the cyclic carbonates, are often used as electrolyte solvents for lithium-ion batteries ${ }^{3)}$, plasticizers $^{4)}$, environmentally friendly aprotic polar organic solvent ${ }^{5)}$, fuel additive ${ }^{6)}$, starting materials and intermediates in the manufacture of fine chemicals ${ }^{7}$.

Carbon dioxide $\left(\mathrm{CO}_{2}\right)$ is an economical, renewable, environmentally friendly and not extensively widely used carbon source in chemical industry ${ }^{8-10}$. And $\mathrm{CO}_{2}$ is a major greenhouse gas, its excessive presence in the air is unfavourable. Up to present, the effective pathway to chemical fixation of $\mathrm{CO}_{2}$ is conducted by the synthesis of five-membered cyclic carbonates through cycloaddition of $\mathrm{CO}_{2}$ to epoxides, which has become one of the most promising synthesis routes for the utilization of $\mathrm{CO}_{2}{ }^{11)}$.

The cycloaddition of $\mathrm{CO}_{2}$ to epoxides is a catalyst reaction, which depends on the type of catalysts. Therefore, the biggest challenge is to develop efficient catalyst that promote the cycloaddition reaction under moderate reaction conditions. Over the past decades, a lot of researchers have focused on development of efficient catalyst system for these reactions ${ }^{12)}$. Due to high catalytic activity, homogeneous catalysts, such as quaternary ammonium salts ${ }^{13,14)}$, metal complexes ${ }^{15,16)}$ and ionic liquids ${ }^{17)}$, organocatalysts $\left.{ }^{18}\right)^{\prime}$, crown ether complexs ${ }^{19)}$, polyethylene glycol ${ }^{20)}$, have received many attentions. Therefore, it is highly desirable to explore a simple and efficient catalyst system for this important transformation.

Deep eutectic solvents (DESs) was first proposed by Abbott in 2003, which aroused the interest of the scientific community immediately. DESs can be obtained by simply mixing together two safe components (e.g. choline chloride and urea), which are capable of forming a eutectic mixture through hydrogen bond interactions ${ }^{21}$. DESs are widely used as extraction solvents ${ }^{22,23)}$, reaction medium ${ }^{24)}$ and catalysts $^{25}$. Additionally, DESs can be also used to separate and capture of acidic gases, such as $\mathrm{CO}_{2}{ }^{26)}$.

As we all known, the methyl soyate is one of the typical vegetable oil fatty acid methyl esters prepared from soybean oil. In addition, carbonated methyl soyates represents a useful and sustainable biobased chemical intermediate for the preparation of functional fluids, fuel additives, and other bio-based products. Up to now, there are limited examples to investigate carbonation of epoxidized methyl soyates in deep eutectic solvents. In the present work, we explored the catalytic performance of TBAB-based DESs

*Correspondence to: Wei Liu, College of Food Science and Technology, Henan University of Technology, Lianhua Street 100, Zhengzhou 450001, P. R. CHINA

E-mail: liuwei307@ hotmail.com

Accepted December 18, 2017 (received for review August 28, 2017)

Journal of Oleo Science ISSN 1345-8957 print / ISSN 1347-3352 online

http://www.jstage.jst.go.jp/browse/jos/ http://mc.manusriptcentral.com/jjocs 


\section{W. Liu and G. Lu}

for cycloaddition of $\mathrm{CO}_{2}$ to epoxidized methyl soyates to produce the carbonated methyl soyates. In particular, the TBAB-based DES play the role of both solvent and promotor, which can efficiently mediated the cycloaddition. And the product of carbonated methyl soyates was confirmed by FT-IR and NMR.

\section{Materials and methods \\ 2.1 Materials}

$\mathrm{CO}_{2}(99.995 \%)$ was supplied by Dumaoai Purge Gas Co. (Shanghai, China). Epoxidized soybean oil (CP) was purchased from Aladdin (Shanghai, China). Tetrabutylammonium bromide (TBAB, $99.0 \%$ ), triethylene glycol $(99.0 \%)$, laevulinic acid $(99.0 \%)$ and decanoic acid $(99.0 \%)$ were obtained from Macklin Bio-Chem Technology Co. (Shanghai, China). Tetrabutylammonium chloride (TBAC, AR) , 1.2-propanediol (AR), oleic acid (AR) and ethylene glycol (AR) were purchased from Kermel Chemical Reagent Co. (Tianjin, China).

\subsection{Preparation of epoxidized methyl soyates}

Epoxidized methyl soyates were prepared as described in the literature ${ }^{27)}$. Briefly, $200.0 \mathrm{~g}$ epoxidized soybean oil was loaded into a 1000-mL three-necked round-bottom flasks along with a mechanical stirrer. Sodium methoxide catalyst, $2.0 \mathrm{~g}(1 \mathrm{wt} \%)$, was dissolved in $60 \mathrm{~mL}$ methanol and then added to the epoxidized soybean oil in the reactor. The transesterification reaction was performed at $50^{\circ} \mathrm{C}$ for $2 \mathrm{~h}$ with suitable speed. After the reaction was completed, the epoxidized methyl soyates were obtained by static separation, water washing and drying treatment. Finally, solvent and trace water were removed with the rotary evaporator. The purity of the epoxidized methyl soyates was determined and analyzed by gas chromatography (Agilent 7890B) equipped with a DB-1HT capillary column $(29.0 \mathrm{~m} \times 250 \mu \mathrm{m} \times 0.1 \mu \mathrm{m})$ and a flame ionization detector (FID). Finally, the purity of the reaction substrate (epoxidized methyl soyates) reached above $98.0 \%$.

\subsection{Synthesis of DESs}

In this work, 11 kinds of binary DESs, which were composed of a hydrogen bond acceptor (tetrabutylammonium bromide or tetrabutylammonium chloride) and hydrogen bond donors (ethylene glycol, 1,2-propanediol, triethylene glycol, levulinic acid, decanoic acid and oleic acid) were obtained through a mixing-heating step at $80^{\circ} \mathrm{C}$ in an oil bath until a homogeneous and stable liquid was formed (Table 1). In particular, when the molar ratio of tetrabutylammonium bromide (TBAB) and ethylene glycol was 1:1, the appearance of the mixture was white solid and opaque when it was cooled to room temperature. In other words, the mixture of TBAB- ethylene glycol with molar ratio of 1:1 is
Table 1 The compositions of binary TBAB-based DESs.

\begin{tabular}{cccc}
\hline Abbreviation & Salt & HBD & $\begin{array}{c}\text { Ratio } \\
(\mathrm{mol} / \mathrm{mol})\end{array}$ \\
\hline DES-1 & TBAB & Ethylene glycol & $1: 2$ \\
DES-2 & TBAB & Ethylene glycol & $1: 4$ \\
DES-3 & TBAB & Ethylene glycol & $1: 6$ \\
DES-4 & TBAB & 1,2-Propanediol & $1: 2$ \\
DES-5 & TBAB & 1,2-Propanediol & $1: 4$ \\
DES-6 & TBAB & 1,2-Propanediol & $1: 6$ \\
DES-7 & TBAB & Triethylene glycol & $1: 1$ \\
DES-8 & TBAC & Triethylene glycol & $1: 1$ \\
DES-9 & TBAB & Levulinic acid & $1: 3$ \\
DES-10 & TBAB & Decanoic acid & $1: 2$ \\
DES-11 & TBAB & Oleic acid & $1: 2$ \\
\hline
\end{tabular}

unable to form DES. Thus, the molar ratio of TBAB and ethylene glycol used in this experiment are 1:2, 1:4 and 1:6.

\subsection{Synthesis of carbonated methyl soyates}

$5.0 \mathrm{~g}$ of epoxidized methyl soyates (epoxide number $=$ 6.20, i.e. 0.01938 mol epoxides) and TBAB-based DESs were added to the Parr stainless steel autoclave equipped with gas inlet tube and outlet, and the autoclave was sealed. Before the reaction was started, the air in the autoclave was replaced by carbon dioxide $\left(\mathrm{CO}_{2}\right)$ three times in order to clean out the air completely. Then the autoclave was heated to the desired reaction temperature and maintained for $10 \mathrm{~min}$. At the moment, the reaction mixture was pressured with $\mathrm{CO}_{2}$ to a definite value at a specific stirring speed, and kept for different reaction time. At the end of the reaction, the autoclave was cooled to room temperature and the unreacted $\mathrm{CO}_{2}$ was vented out. The DES was completely removed by dissolving the reaction mixture in ethyl acetate and washing the reaction mixture three times with water. The organic layer was dried with anhydrous sodium sulfate. The solvent and trace water in the organic layer was then distilled under reduced pressure with the rotary evaporator.

\subsection{Characterization of the product}

The addition of $\mathrm{CO}_{2}$ to the epoxidized group to form the five-membered cyclic carbonate group was confirmed by React $\mathrm{IR}^{\mathrm{TM}}$. Characteristic epoxide peaks of epoxidized methyl soyates are noted at $842-822 \mathrm{~cm}^{-1}$. As expected, the React $\mathrm{IR}^{\mathrm{TM}}$ spectrum of carbonated methyl soyates lacks these epoxide peaks, while the appearance of an strong absorption peak at $1,800-1,804 \mathrm{~cm}^{-1}(\mathrm{C}=\mathrm{O}$ bond $)$ is carbonate. Formation of the carbonate and the disappearance of the epoxide structures were also confirmed by ${ }^{1} \mathrm{H}-\mathrm{NMR}$ and ${ }^{13} \mathrm{C}$-NMR analysis. ${ }^{1} \mathrm{H}-\mathrm{NMR}$ inspection and ${ }^{13} \mathrm{C}-\mathrm{NMR}$ inspection, samples were prepared by dissolving a 
certain amount of products in $\mathrm{CDCl}_{3}$. Both of ${ }^{1} \mathrm{H}-\mathrm{NMR}$ and ${ }^{13} \mathrm{C}-\mathrm{NMR}$ analysis were recorded using a Bruker Avance III HD 500 NMR spectrometer (Swiss) operating at a frequency of $500 \mathrm{MHz}$ with tetramethylsilane (TMS) as the internal standard.

The epoxidized oxygen group content (EOC) of epoxidized methyl soyates determination was carried out by the direct method with hydrobromic acid solution in acetic $\operatorname{acid}^{28)}$.

\section{Results and discussions}

As we all known, the cycloaddition reaction of epoxides and carbon dioxide is a gas-liquid two-phase reaction. Since the solubility of carbon dioxide in epoxides is not very well, many reaction systems used organic solvents or additives to improve the mass transfer of the reaction, thus enhancing the efficiency of the reaction ${ }^{13,29)}$. However, the use of organic solvents is not environmentally friendly and increases the production costs. To the best of our knowledge, tetrabutylammonium bromide (TBAB) is one of the most widely used catalysts for chemical fixation of $\mathrm{CO}_{2}$ to epoxides to form cyclic carbonate ${ }^{30-34)}$. Therefore, in this work, cycloaddition reaction of $\mathrm{CO}_{2}$ with epoxidized methyl soyates was performed in the presence of TBAB-based DESs.

The proposed scheme for cycloaddition reaction of $\mathrm{CO}_{2}$ and epoxidized methyl soyates mediated by TBAB-based DESs is shown in Scheme 1.

\subsection{Selection of the TBAB-based DESs}

DESs are now widely acknowledged as a new kind of ionic liquid (IL) analogues. Due to their biocompatibility, renewability, biodegradability and easy synthesis, DESs are often presented as a more economical and eco-friendly alternative to ionic liquid ${ }^{35)}$. DESs are usually obtained by the complexation of a quaternary ammonium salt with metal salt or hydrogen bond donor $(\mathrm{HBD})^{21)}$. In this work, six types of HBD (ethylene glycol, 1,2-propanediol, triethylene glycol, levulinic acid, decanoic acid and oleic acid) were used to combine with TBAB to prepare TBAB-based DESs. Then the TBAB-based DESs were used as the catalyst for the chemical fixation of $\mathrm{CO}_{2}$ to epoxidized methyl

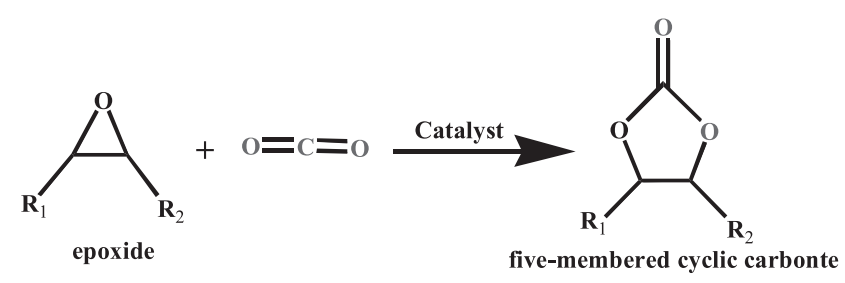

Scheme 1 Reaction scheme of cycloaddition of $\mathrm{CO}_{2}$ to epoxides.

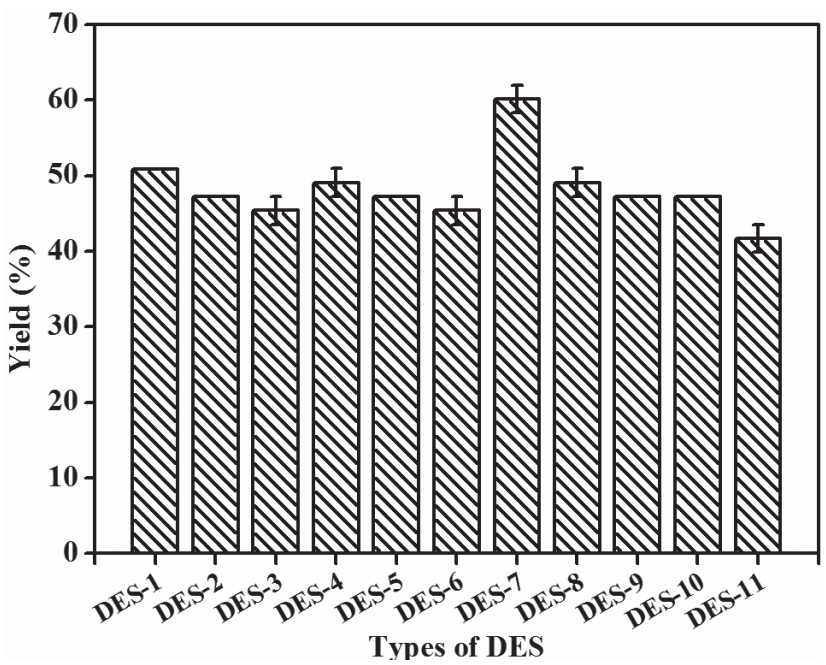

Fig. 1 The effect of different TBAB-based DESs on cycloaddition reaction of epoxidized methyl soyates with $\mathrm{CO}_{2}$. Reaction conditions: reaction temperature: $100^{\circ} \mathrm{C}$; reaction time: $10 \mathrm{~h} ; \mathrm{CO}_{2}$ pressure: $1.0 \mathrm{MPa}$; stirring speed: $400 \mathrm{rpm}$; catalyst concentration: 0.04 mol TBAB per mol of epoxidized group.

soyates to prepare the corresponding five-membered cyclic carbonates, carbonated methyl soyates. The catalytic effect of different TBAB-based DESs was shown in Fig. 1.

The different kinds of HBDs lead to differences in physicochemical properties of the formed TBAB-based DESs ${ }^{36}$, such as viscosity, polarity, melting point and solubility, etc. The experimental results shown in Fig. 1 demonstrated that DES-7 (TBAB/TEG) has the best catalytic activity for the cycloaddition reaction of the epoxidized methyl soyates with $\mathrm{CO}_{2}$ under the identical reaction conditions, compared with other examined DESs. When the DES-7 was replaced with DES-8 (TBAC/TEG), the cycloaddition reaction afforded lower yield (49\%). The obtained results suggested that bromide ion indeed played crucial role in the catalytic process $^{37)}$. Therefore, DES-7 (TBAB/TEG) was selected as the best solvent to promote the cycloaddition reaction of epoxidized methyl soyates with $\mathrm{CO}_{2}$ in the following experiments.

\subsection{Effect of the concentration of DES}

In the present work, the DES-7 acted as both a solvent and a promotor. Since the reaction is a gas-liquid twophase reaction, the contact area between gaseous $\mathrm{CO}_{2}$ and the substrate is the key to the promote this reaction. Many studies have shown that DES has the ability to capture and separate acidic gases ${ }^{26,38)}$. When $\mathrm{CO}_{2}$ was dissolved into DES, the DES was blended with epoxidized methyl soyates at a suitable stirring rate, thereby increasing the contact area with the epoxidized methyl soyates. Therefore, different concentrations of TBAB-based DES would lead to dif- 


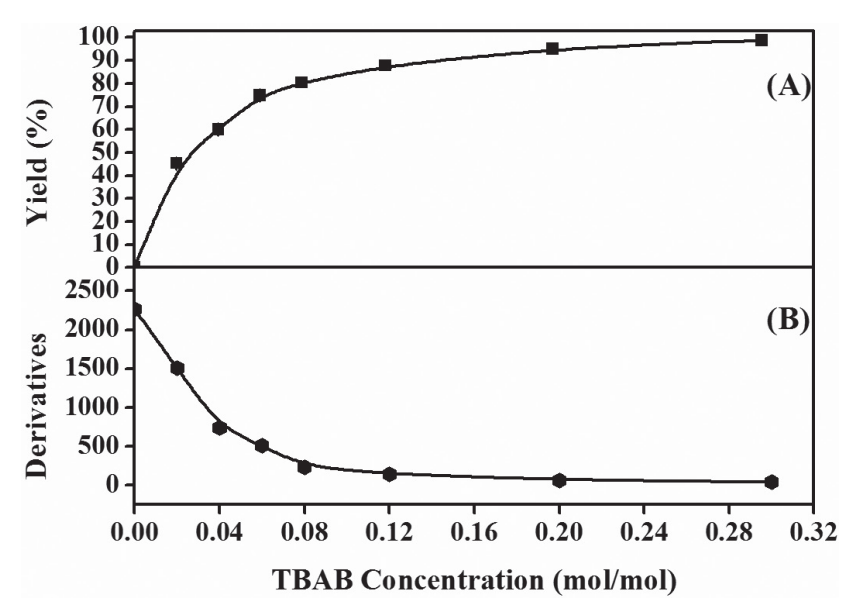

Fig. 2 The effect of TBAB concentration on cycloaddition reaction of epoxidized methyl soyates with $\mathrm{CO}_{2}$. Reaction conditions: reaction temperature: $100^{\circ} \mathrm{C}$; reaction time: $10 \mathrm{~h}$; $\mathrm{CO}_{2}$ pressure: $1.0 \mathrm{MPa}$; stirring speed: $400 \mathrm{rpm}$.

ferent absorption amounts of $\mathrm{CO}_{2}$, which affected the reaction rate of cycloaddition reaction obviously (Fig. 2).

A set of experiments were performed and the results were shown in Fig. 2. The experimental results demonstrated that the yields of carbonated methyl soyates increased sharply with the molar amount of the catalyst before it reached 0.08 times the molar amount of epoxidized group. Further increasing the molar amount of the catalyst after it reached 0.12 times that of epoxidized group, the reaction rate increased slowly, and gradually approaching 0 (as shown in Fig. $2 \mathrm{~B}$ ). When the catalyst concentration was 0.12 , the yield of carbonated methyl soyates could reach $88 \%$. Therefore, the optimum DES amount was 0.12 times the molar amount of epoxidized group, and was used in the following experiments.

\subsection{Effect of the reaction temperature}

The reaction temperature was one of the critical factors for this cycloaddition reaction. Since the epoxidized groups of epoxidized methyl soyates are located in the middle of the molecular chain rather than in terminal position, and the steric hindrance exists in the substrates led to higher reaction temperature. Therefore, the effect of reaction temperature $\left(60^{\circ} \mathrm{C}, 80^{\circ} \mathrm{C}, 100^{\circ} \mathrm{C}, 120^{\circ} \mathrm{C}\right.$ and $\left.140^{\circ} \mathrm{C}\right)$ on the cycloaddition reaction of epoxidized methyl soyates with $\mathrm{CO}_{2}$ was investigated (Fig. 3) . At $60^{\circ} \mathrm{C}$, no cycloaddition reaction was detected. When the reaction temperature was increased from $80^{\circ} \mathrm{C}$ to $120^{\circ} \mathrm{C}$, the product yield was increased from $40 \%$ to $93 \%$. However, the yield of carbonated methyl soyates was decreased with further increasing of the reaction temperature $\left(140^{\circ} \mathrm{C}\right)$. This is because that the TBAB can readily decompose into volatile compounds such as hydrogen bromide, which is highly reactive with epoxidized groups. Zheng and his co-workers ${ }^{39)}$ have demon-

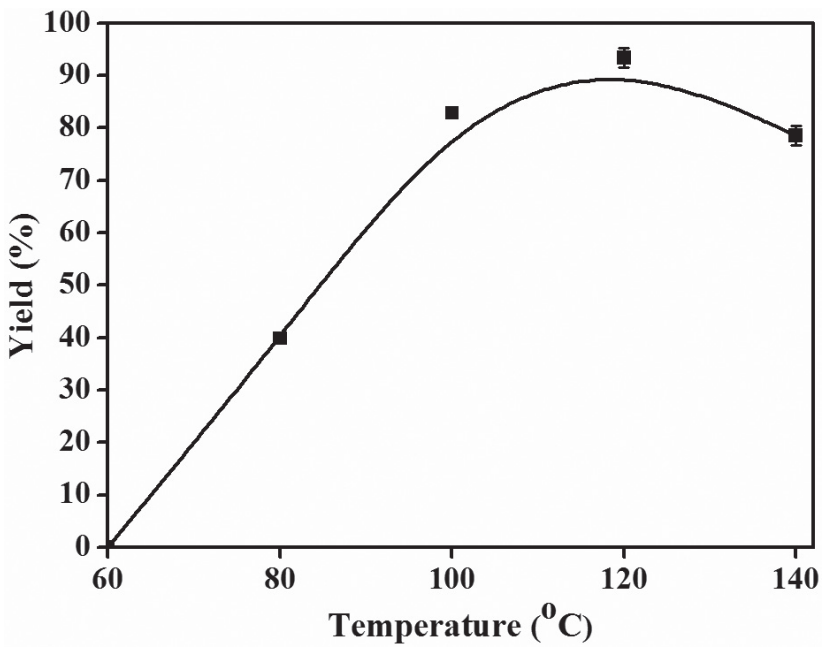

Fig. 3 The effect of reaction temperature on cycloaddition reaction of epoxidized methyl soyates with $\mathrm{CO}_{2}$. Reaction conditions: the TBAB concentration of 0.12 ; reaction time: $10 \mathrm{~h}$; $\mathrm{CO}_{2}$ pressure: $1.0 \mathrm{MPa}$; stirring speed: $400 \mathrm{rpm}$.

strated that the maximum reaction temperature should not exceed $130^{\circ} \mathrm{C}$ during the TBAB catalyzed cycloaddition of $\mathrm{CO}_{2}$ to epoxidized vegetable oils. Therefore, an operation temperature of $120^{\circ} \mathrm{C}$ was chosen as the optimum reaction temperature.

\subsection{Effect of the reaction time}

The effect of reaction time on cycloaddition reaction of epoxidized methyl soyate was also investigated and the experimental results were shown in Fig. 4. The experiments

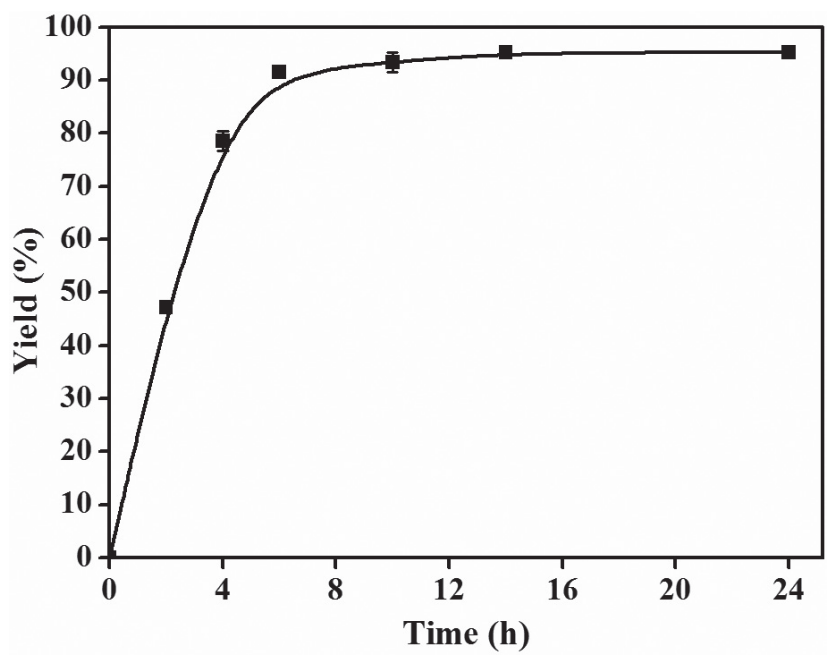

Fig. 4 The effect of reaction time on cycloaddition reaction of epoxidized methyl soyates with $\mathrm{CO}_{2}$. Reaction conditions: the TBAB concentration of 0.12 ; reaction temperature: $120^{\circ} \mathrm{C}$; $\mathrm{CO}_{2}$ pressure: 1.0 MPa; stirring speed: $400 \mathrm{rpm}$. 
were performed under a $\mathrm{CO}_{2}$ atmosphere with $1.0 \mathrm{MPa}$ pressure using DES-7 as the promotor/solvent to investigate the effect of different reaction time on the cycloaddition process.

The yield of carbonated methyl soyates were increased rapidly with the reaction time before it reached $6 \mathrm{~h}$. The rate of the cycloaddition reaction shows a first-order dependence with respect to the EMSs concentration and the rate constants was $0.0070 \mathrm{~min}^{-1}$. However, further increasing the reaction time $(10-14 \mathrm{~h})$, the rate of cycloaddition reaction was increased slowly, and gradually became horizontal eventually. When the reaction time was reached 10 $\mathrm{h}$, the yield of carbonated methyl soyates was $95 \%$. The result was similar with the results of much longer reaction time $(14 \mathrm{~h})$ and it was not necessary to prolong the reaction time. Therefore, an operation time of $10 \mathrm{~h}$ was chosen as the optimum reaction time.

\subsection{Effect of the $\mathrm{CO} 2$ pressure}

The $\mathrm{CO}_{2}$ pressure was one of the key factors for this cycloaddition of $\mathrm{CO}_{2}$ to epoxidized methyl soyates. This is due to the solubility of $\mathrm{CO}_{2}$ in DES and epoxidized methyl soyates has a great relationship with pressure ${ }^{26,40)}$. The difference in pressure caused the amount of carbon dioxide to dissolve in the reaction mixture. In order to investigate the relationship between $\mathrm{CO}_{2}$ pressure and product yield, a set of experiments were conducted under different $\mathrm{CO}_{2}$ pressure (0.1 MPa, 0.5 $\mathrm{MPa}$ and 1.0 MPa). The experimental results were presented in Fig. 5.

It is obvious that the $\mathrm{CO}_{2}$ pressure has a relatively high impact on the yield of carbonated methyl soyates. It can be seen that the $\mathrm{CO}_{2}$ pressure was $0.1 \mathrm{MPa}$, the yield of the

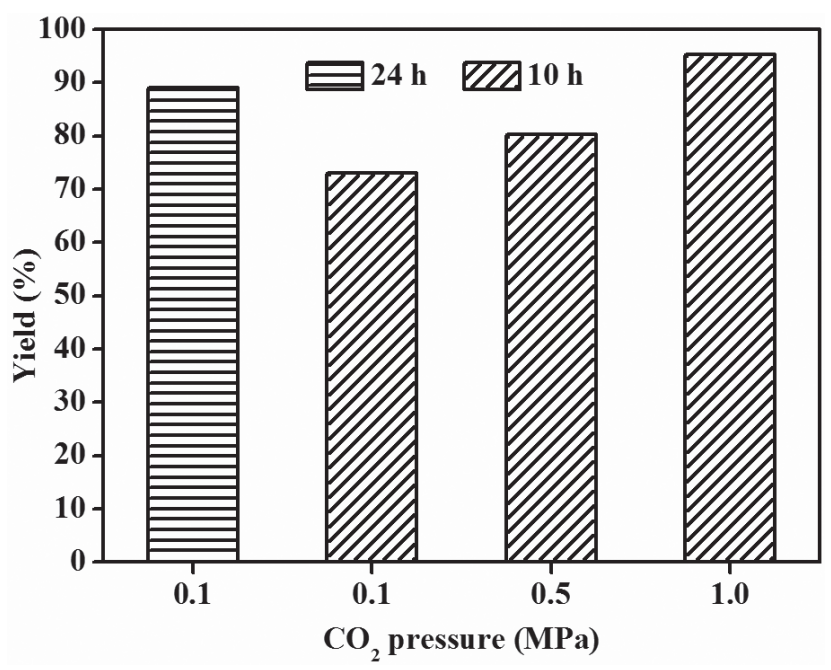

Fig. 5 The effect of $\mathrm{CO}_{2}$ pressure on cycloaddition reaction of epoxidized methyl soyates with $\mathrm{CO}_{2}$. Reaction conditions: the TBAB concentration of 0.12 ; reaction temperature: $120^{\circ} \mathrm{C}$; stirring speed: $400 \mathrm{rpm}$. product was $73 \%$. When the $\mathrm{CO}_{2}$ pressure was increased to $0.5 \mathrm{MPa}, 80 \%$ yield of carbonated methyl soyates was obtained. Increasing the $\mathrm{CO}_{2}$ pressure to $1.0 \mathrm{MPa}$, the yield of carbonated methyl soyates was increased to $95 \%$. In addition, prolonging this cycloaddition reaction time from 12 $\mathrm{h}$ to $24 \mathrm{~h}$ on the conditions of $0.1 \mathrm{MPa}$ pressure of $\mathrm{CO}_{2}$, the yield of carbonated methyl soyates was $89 \%$. Considering the yield and time cost, $1.0 \mathrm{MPa}$ pressure of $\mathrm{CO}_{2}$ was selected as the optimum operation pressure.

\subsection{Comparison the effects of TBAB and TBAB-based DES}

In order to compare the effects of TBAB and TBABbased DES (TBAB/TEG) on the cycloaddition of $\mathrm{CO}_{2}$ to epoxidized methyl soyates, a control experiment was conducted (Fig. 6).

Figure 6 clearly indicated that the effect of TBAB-based DES (TBAB/TEG) on the yield of product was better than the use of TBAB alone, which suggested that the catalytic effect of DES (TBAB/TEG) on cycloaddition reaction of epoxidized methyl soyates and $\mathrm{CO}_{2}$ is obviously better than the effect of using TBAB alone. The reason for this result was that the DES (TBAB/TEG) has certain capability to capture $\mathrm{CO}_{2}^{38)}$, thus the DES roled both as a promotor and a solvent. The properties of TBAB-based DES are helpful to the mass transfer between gas and liquid, which is beneficial to promote progress of this cycloaddition reaction. Furthermore, when the reaction time was between 0 and 2 $\mathrm{h}$, the rate constants of the cycloaddition reaction mediated by TBAB and the DES (TBAB/TEG) were $0.0066 \mathrm{~min}^{-1}$ and $0.011 \mathrm{~min}^{-1}$, respectively. In addition, Fig. 6 showed that the yield of carbonated methyl soyates was increased rapidly and then the reaction rate became slower with prolonging of the reaction time. This is because the absorption rate of $\mathrm{CO}_{2}$ increases in the following order: epoxidized

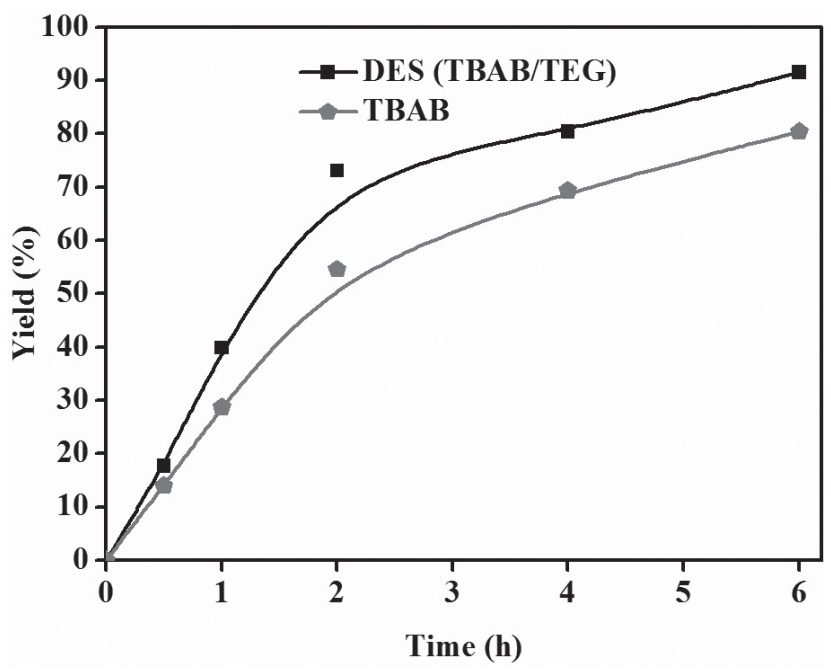

Fig. 6 Comparison the effects of TBAB and DES (TBAB/ TEG). 
vegetable oils $>$ carbonated vegetable oils ${ }^{40)}$. As the cycloaddition reaction proceeded, the epoxidized methyl soyates were consumed, and the carbonated methyl soyates were increased, which led to a slower absorption rate of $\mathrm{CO}_{2}$. Therefore, the yield of the product increased rapidly and then increased slowly.

\subsection{Characterization of product}

The product of carbonated methyl soyates was characterized by FT-IR, ${ }^{1} \mathrm{H}-\mathrm{NMR}$ and ${ }^{13} \mathrm{C}-\mathrm{NMR}$. Firstly, from FT-IR spectroscopy, we can clearly observe the substrate after and before the cycloaddition reaction is different (Fig. 7). The FT-IR spectra clearly showed the generation of a new bond at $1,801 \mathrm{~cm}^{-1}(\mathrm{C}=\mathrm{O}$ stretching $)$, associating with the five-membered cyclic carbonates formation, which was larger than the carbonyl bond of the triglyceride backbone at $1,730 \mathrm{~cm}^{-1}(\mathrm{C}=\mathrm{O}$ stretching $)$. The carbonyl bonds $\left(1,730 \mathrm{~cm}^{-1}\right)$ of ester bond are present in both the raw material (epoxidized methyl soyates) and the product (carbonated methyl soyates) without any change.

Subsequently, ${ }^{1} \mathrm{H}$-NMR was used to further determine the cycloaddition reaction of epoxidized methyl soyates with $\mathrm{CO}_{2}$. The ${ }^{1} \mathrm{H}-\mathrm{NMR}$ spectra of epoxidized methyl

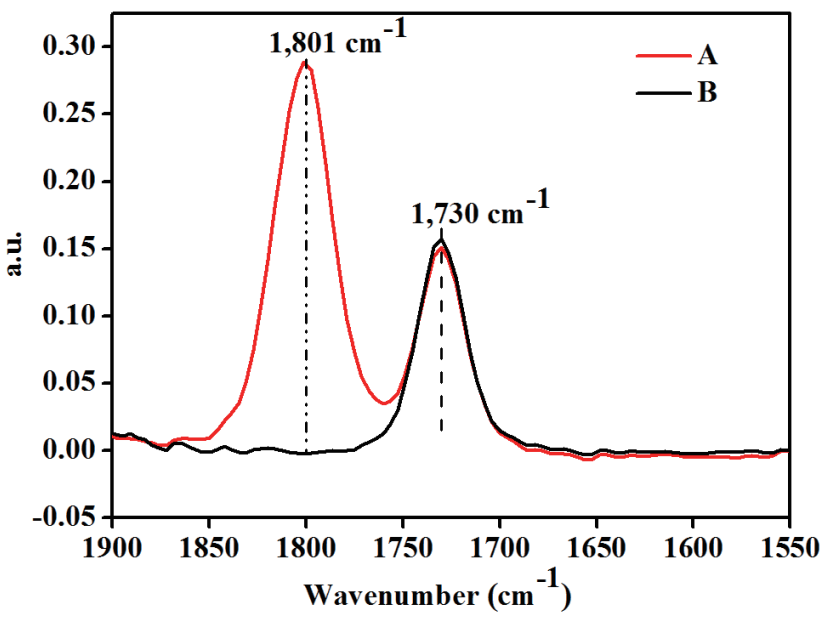

Fig. 7 FT-IR spectra after(A) and before(B) the cycloaddition reaction.

soyates and carbonated methyl soyates clearly indicated the occurrence of the cycloaddition reaction of epoxidized methyl soyates with $\mathrm{CO}_{2}$, which was shown in Fig. 8. The ${ }^{1} \mathrm{H}-\mathrm{NMR}$ signals of the epoxide moiety (at $2.85 \mathrm{ppm}$ and $3.15 \mathrm{ppm}$ ) disappeared. New ${ }^{1} \mathrm{H}-\mathrm{NMR}$ signals associated
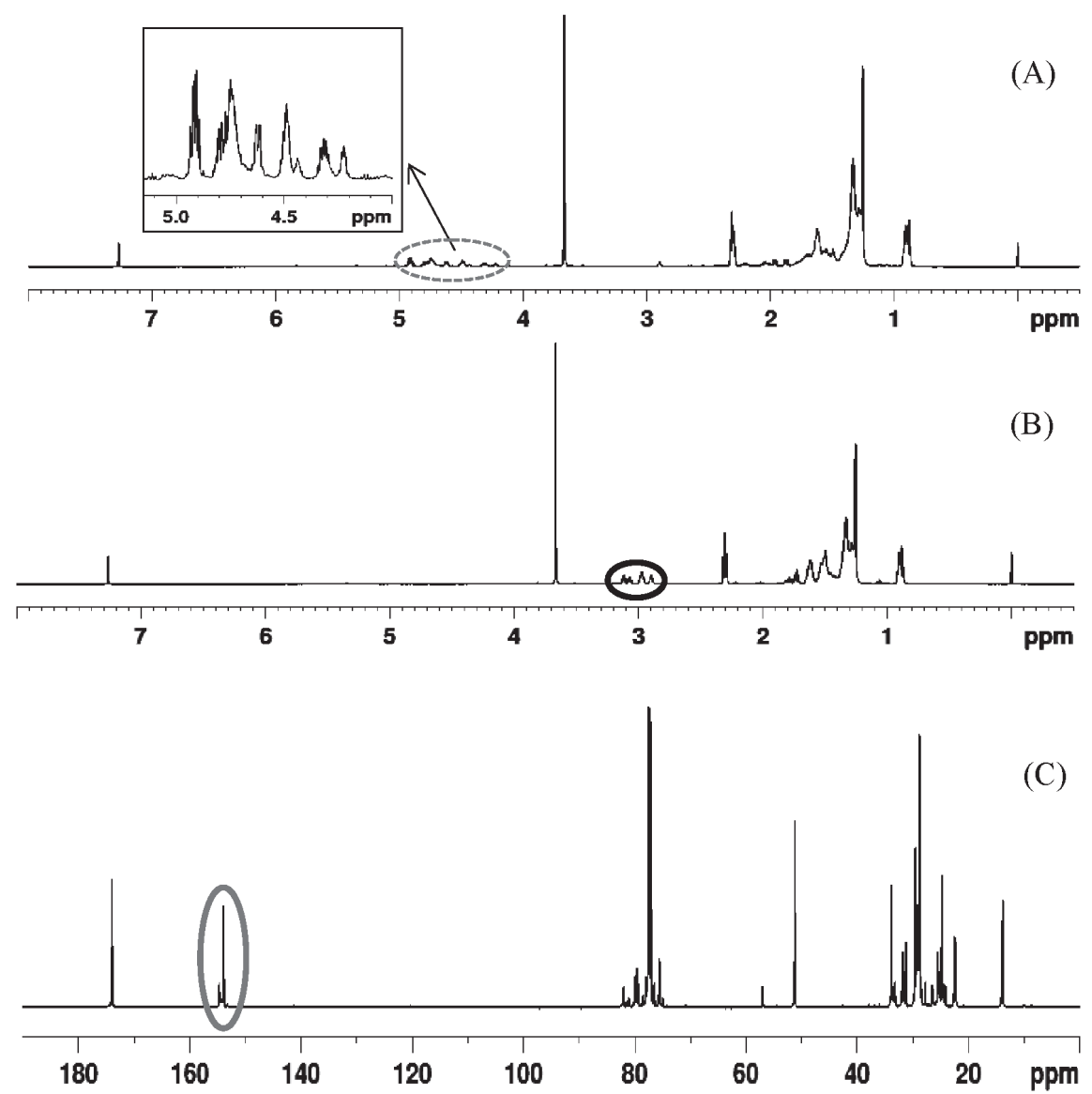

Fig. $8{ }^{1} \mathrm{H}-\mathrm{NMR}$ spectra after(A) and before(B) the cycloaddition reaction and ${ }^{13} \mathrm{C}-\mathrm{NMR}$ spectra (C) of carbonated methyl soyates. 
with the carbonate moiety appeared between 4.20-4.95 ppm.

Finally, the cycloaddition product was also identified by ${ }^{13} \mathrm{C}$-NMR spectroscopy. Figure 8 (c) showed that the ${ }^{13} \mathrm{C}$-NMR spectra of carbonated methyl soyates obtained under the reaction conditions of $120^{\circ} \mathrm{C}, 0.12$ of TBAB concentration, $1.0 \mathrm{MPa}$ pressure of $\mathrm{CO}_{2}$ and $10 \mathrm{~h}$. It became obviously that a new peak appeared at $154 \mathrm{ppm}$, which was associated with carbonate moiety in the five-membered cyclic group in the product.

\section{Conclusions}

Carbonated methyl soyates can be obtained by cycloaddition of $\mathrm{CO}_{2}$ to epoxidized methyl soyate in excellent yield in the presence of TBAB-based DES at $120^{\circ} \mathrm{C}$ and $1.0 \mathrm{MPa}$ pressure of $\mathrm{CO}_{2}$. The control experiments indicated that the DES (TBAB-TEG) roled both as a solvent and a promotor, which showed better activity than the TBAB alone. The TBAB-based DESs possess the characteristic of environmental friendly, cheap, greener, simple preparation, $\mathrm{CO}_{2}$ capture capability and biodegradable compared to conventional catalysts and solvents. The use of TBABbased DES significantly shortened the reaction time of the cycloaddition of $\mathrm{CO}_{2}$ to epoxidized methyl soyates. And the TBAB-based DES (TBAB/TEG) will provide a potential method to promote the cycloaddition reaction of epoxidized compounds with $\mathrm{CO}_{2}$ to form five-membered cyclic carbonated compounds without any co-solvents.

\section{Acknowledgements}

This work was supported by the China Postdoctoral Science Foundation funded project(No. 2017M622364) and Project of Henan University of Technology Excellent Young Teachers (No. 2014003).

\section{Conflict of interest}

The authors declare no competing financial interest.

\section{References}

1) Shaikh, A.A.G.; Sivaram, S. Organic carbonates. Chem. Rev. 96, 951-976 (1996).

2) Schäffner, B.; Schäffner, F.; Verevkin, S.P.; Borner, A. Organic carbonates as solvents in synthesis and catalysis. Chem. Rev. 41, 4554-4581(2010).

3) Wu, S.; Zhang, Y.Y.; Wang, B.S.; Elageed, E.H.M.; Ji, L.Z.; Wu, H.H.; Gao, G. H. Synthesis of functionalized cyclic carbonates by one-pot reactions of carbon dioxide, epibromohydrin, and phenols, thiophenols, or carboxylic acids catalyzed by ionic liquids. Eur. J. Org. Chem. 3, 753-759 (2017).

4) Ziosi, P.; Tabanelli, T.; Fornasari, G.; Cocchi, S.; Cavani, F.; Righi, P. Carbonates as reactants for the production of fine chemicals: The synthesis of 2-phenoxyethanol. Catal. Sci. Technol. 4, 4386-4395(2014).

5) Webster, D.C. Cyclic carbonate functional polymers and their applications. Prog. Org. Coat. 47, 77-86 (2003).

6) Holser, R.A. Carbonation of epoxidized methyl soyate at atmospheric pressure. J. Oleo Sci. 56, 629-632 (2007).

7) Maksimchuk, N.V.; Ivanchikova, I.D.; Ayupov, A.B.; Kholdeeva, O.A. One-step solvent-free synthesis of cyclic carbonates by oxidative carboxylation of styrenes over a recyclable Ti-containing catalyst. Appl. Catal.,B 181, 363-370 (2015).

8) He, M.Y.; Sun, Y.H.; Han, B.X. Green carbon science: Scientific basis for integrating carbon resource processing, utilization, and recycling. Angew. Chem. Int. Edit. 52, 9620-9633 (2013).

9) Aoki, W.; Wattanavinin, N.; Kusumoto, S.; Nozaki, K. Development of highly active Ir-PNP catalysts for hydrogenation of carbon dioxide with organic bases. Bull. Chem. Soc. Jpn. 89, 113-124(2016).

10) Dong, H.J.; Jung, H.; Jeon, S.; Kim, S.H. Effect of amine structure on $\mathrm{CO}_{2}$ adsorption of modified poly (ethyleneimine)-impregnated mesostructured silica sorbents. Bull. Chem. Soc. Jpn. 89, 1462-1469 (2016).

11) Fiorani, G.; Guo, W.S.; Kleij, A.W. Sustainable conversion of carbon dioxide: the advent of organocatalysis. Green Chem. 17, 1375-1389 (2015).

12) Sakakura, T.; Kohno, K. The synthesis of organic carbonates from carbon dioxide. Chem. Commun. 11, 1312-1330 (2009).

13) Li, Z.R.; Zhao, Y.H.; Yan, S.R.; Wang, X.K.; Kang, M.Q.; Wang, J.W.; Xiang, H.W. Catalytic synthesis of carbonated soybean oil. Catal. Lett. 123, 246-251 (2008).

14) Montoya, C.A.; Paninho, A.B.; Felix, P.M.; Zakrzewska, M.E.; Vital, J.; Najdanovic-Visak, V.; Nunes, A.V.M. Styrene carbonate synthesis from $\mathrm{CO}_{2}$ using tetrabutylammonium bromide as a non-supported heterogeneous catalyst phase. J. Supercrit. Fluid 100, 155159 (2015).

15) Castroosma, J.A.; Lamb, K.J.; North, M. Cr (salophen) complex catalyzed cyclic carbonate synthesis at ambient temperature and pressure. ACS Catal. 6, 50125025 (2016).

16) Schwarz H. Metal-mediated activation of carbon dioxide in the gas phase: Mechanistic insight derived from a combined experimental/computational approach. 


\section{W. Liu and G. Lu}

Coord. Chem. Rev. 334, 112-123(2017).

17) Bobbink, F.D.; Dyson, P.J. Synthesis of carbonates and related compounds incorporating $\mathrm{CO}_{2}$ using ionic liquid-type catalysts: State-of-the-art and beyond. J. Catal. 343, 52-61 (2016).

18) Büttner, H.; Steinbauer, J.; Wulf, C.; Dindaroglu, M.; Schmalz, H.G.; Werner, T. Organocatalyzed synthesis of oleochemical carbonates from $\mathrm{CO}_{2}$ and renewables. ChemSusChem 10, 1076-1079 (2017).

19) Desens, W.; Werner, T. Convergent activation concept for $\mathrm{CO}_{2}$ fixation in carbonates. Adv. Synth. Catal. 358, 622-630 (2016).

20) Kaneko, S.; Shirakawa, S. Potassium iodide-tetraethylene glycol complex as a practical catalyst for $\mathrm{CO}_{2}$ fixation reactions with epoxides under mild conditions. ACS Sustain. Chem. Eng. 5, 2836-2840(2017).

21) Smith, E.L.; Abbott, A.P.; Ryder, K.S. Deep eutectic solvents (DESs) and their applications. Chem. Rev. 114, 11060-11082(2014).

22) Pang, K.; Hou, Y.C.; Wu, W.J.; Peng, W.; Marsh, H.N. Efficient separation of phenols from oils via forming deep eutectic solvents. Green Chem. 14, 2398-2401 (2012).

23) Shahbaz, K.; Mjalli, F.S.; Hashim, M.A.; AINashef, I.M. Eutectic solvents for the removal of residual palm oilbased biodiesel catalyst. Sep. Purif. Technol. 81, 216222 (2011).

24) Garcíaálvarez, J. Deep eutectic solvents: Environmentally friendly media for metal-catalyzed organic reactions. ACS Sym. Ser. 1186, 37-52(2014).

25) Liu, P.; Hao, J.W.; Mo, L.P.; Zhang, Z.H. Recent advances in the application of deep eutectic solvents as sustainable media as well as catalysts in organic reactions. RSC Adv. 5, 48675-48704(2015).

26) Gutiérrez, M.C.; Carriazo, D.; Ania, C.O.; Parra, J.B.; Ferrer, M.L.; Monte, F.D. Deep eutectic solvents as both precursors and structure directing agents in the synthesis of nitrogen doped hierarchical carbons highly suitable for $\mathrm{CO}_{2}$ capture. Energ. Environ. Sci. 4, 3535-3544(2011).

27) Holser, R.A. Transesterification of epoxidized soybean oil to prepare epoxy methyl esters. Ind. Crop. Prod. 27, 130-132 (2008).

28) Paquot, C. Standard methods for the analysis of oils, fats and derivatives part 1. 6th ed. Pergamon, Oxford, pp. 66-70 (1979).

29) Xiao, L.F.; Li, F.W.; Xia, C.G. An easily recoverable and efficient natural biopolymer-supported zinc chloride catalyst system for the chemical fixation of carbon dioxide to cyclic carbonate. Appl. Catal., A 279, 125129 (2005).

30) Mazo, P.; Rios, L. Carbonation of epoxidized soybean oil improved by the addition of water. J. Am. Oil Chem. Soc. 90, 725-730(2013).

31) Sun, J.M.; Fujita, S.I.F.; Zhao, F.Y.; Arai, M. A highly efficient catalyst system of $\mathrm{ZnBr}_{2} / \mathrm{n}-\mathrm{Bu}_{4} \mathrm{NI}$ for the synthesis of styrene carbonate from styrene oxide and supercritical carbon dioxide. Appl. Catal., A 287, 221226 (2005).

32) Doll, K.M.; Erhan, S.Z. The improved synthesis of carbonated soybean oil using supercritical carbon dioxide at a reduced reaction time. Green Chem. 7, 849-854 (2005).

33) Sun, J.M.; Fujita, S.I.; Bhanage, B.M.; Arai, M. One-pot synthesis of styrene carbonate from styrene in tetrabutylammonium bromide. Catal. Today 93, 383-388 (2004).

34) Caló, V.; Nacci, A.; Monopoli, A.; Fanizzi, A. Cyclic carbonate formation from carbon dioxide and oxiranes in tetrabutylammonium halides as solvents and catalysts. Org. Lett. 4, 2561-2563(2002).

35) Troter, D.Z.; Todorović, Z.B.; Đokić-Stojanović, D.R.; Stamenković, O.S.; Veljković, V.B. Application of ionic liquids and deep eutectic solvents in biodiesel production: A review. Renew. Sust. Energ. Rev. 61, 473-500 (2016).

36) Yusof, R.; Abdulmalek, E.; Sirat, K.; Rahman, M.B.A. Tetrabutylammonium bromide (TBABr) -based deep eutectic solvents (DESs) and their physical properties. Molecules 19, 8011-8026 (2014).

37) Supasitmongkol, S.; Styring, P. A single centre aluminium (III) catalyst and TBAB as an ionic organo-catalyst for the homogeneous catalytic synthesis of styrene carbonate. Catal. Sci. Technol. 4, 1622-1630(2014).

38) Wise, M.; Chapoy, A. Carbon dioxide solubility in triethylene glycol and aqueous solutions. Fluid Phase Equilibr. 419, 39-49(2016).

39) Zheng, J.L.; Burel, F.; Salmi, T.; Taouk, B.; Leveneur, S. Carbonation of vegetable oils: Influence of mass transfer on reaction kinetics. Ind. Eng. Chem. Res. 54, 10935-10944(2015).

40) Cai, X.S.; Zheng, J.L.; Wärnå, J.; Salmi, T.; Taouk, B.; Leveneur, S. Influence of gas-liquid mass transfer on kinetic modeling: carbonation of epoxidized vegetable oils. Chem. Eng. J. 313, 1168-1183(2017). 